\title{
Marcadores Genéticos e Auto-Imunes do Diabetes Melito Tipo 1: da Teoria para a Prática
}

\section{Maria Elizabeth Rossi da Silva DENISE MORY ELAINE DAVINI}

Hospital das Clínicas da Faculdade de Medicina da Universidade de São Paulo (HC-FMUSP), SP, Brasil (MERS, ED); Disciplina de Endocrinologia da Escola Paulista de Medicina da Universidade Federal de São Paulo (Unifesp/EPM) (DM), SP, Brasil.

Recebido em 14/01/2008 Aceito em 21/01/2008

\author{
RESUMO
}

O diabetes melito tipo 1 auto-imune (DM1A) resulta da destruição auto-imune seletiva das células-beta pancreáticas produtoras de insulina. $O$ principal determinante genético de suscetibilidade para o DM1A está em genes do complexo principal de histocompatibilidade, no cromossomo 6p211.3 (locus IDDM1), responsável por $40 \%$ ou mais da agregação familiar dessa doença. O maior risco é conferido pelo genótipo do antígeno leucocitário humano HLA-DR3-DQA1* 0501-DQB1*0201/DR4-DQA1*0301-QB1*0302, e o haplótipo HLA-DR15-DQA1* 0102-DQB1*0602 é associado à proteção. Três outros loci relacionados à predisposição a DM1A são o número variável de freqüências repetidas (VNTR) do gene da insulina (IDDM2), que confere $10 \%$ da suscetibilidade genética, o antígeno-4 associado ao linfócito T citotóxico (CTLA-4) e o protein tyrosine phosphatasis nonreceptor-type 22 (PTPN22). Muitos outros genes suspeitos de predispor à auto-imunidade estão sendo investigados. O DM1A é freqüentemente associado com doença auto-imune tiroidiana, doença celíaca, doença de Addison e várias outras doenças auto-imunes, caracterizadas por auto-anticorpos órgãos-específicos, relacionados aos mesmos determinantes genéticos. Esses anticorpos são úteis na deteç̧ão de auto-imunidade órgão-específica antes do aparecimento da doença clínica, prevenindo comorbidades. (Arq Bras Endocrinol Metab 2008;52/2:166-180)

Descritores: Diabetes tipo 1A; Genes; Auto-imunidade; Marcadores

\section{ABSTRACT}

\section{Genetic and Humoral Autoimmunity Markers of Type 1 Diabetes: From Theory to Practice.}

Type $1 \mathrm{~A}$ diabetes mellitus (T1AD) results from the autoimmune destruction of the insulin producing pancreatic beta-cells. The largest contribution to genetic susceptibility comes from several genes located in the major histocompatibility complex on chromosome 6p21.3 (IDDM1 locus), accounting for at least $40 \%$ of the family aggregation of this disease. The highest-risk human leukocyte antigen HLA genotype for T1AD is DR3-DQA1*0501-DQB1*0201/ DR4-DQA 1*0301-DQB1*0302, whereas -DR15-DQA 1*0102-DQB1*0602 haplotype is associated with dominant protection. Three other T1D loci associated with predisposition are the Variable Number for Tandem Repeats (VNTR) near the insulin gene (IDDM2), which accounts to $10 \%$ of genetic susceptibility, the Cytotoxic T-Lymphocyte-associated Antigen (CTLA-4)(IDDM 12) and the Protein Tyrosine Phosphatasis Nonreceptor-type 22 (PTPN22). Many other gene suspected to predispose to autoimmunity have been investigated. T1AD is frequently associated with autoimmune thyroid disease, celiac disase, Addison's disease and many other autoimmune diseases, characterized by organ-specific autoantibodies and related to the same genetic background. Using these autoantibodies, organ specific autoimmunity may be detected before the development of clinical disease preventing significant morbidity. (Arq Bras Endocrinol Metab 2008;52/2:166-180)

Keywords: Type 1 A diabetes; Genes; Autoimmunity; Markers 


\section{INTRODUÇÃO}

O DiABETES MELITO TIPO 1 auto-imune (DMIA) representa $5 \%$ a $10 \%$ dos casos de diabetes e decorre da destruição auto-imune seletiva das células-beta das ilhotas pancreáticas. $\mathrm{O}$ grau de destruição celular é variável. É rápido e intenso em crianças e adolescentes, resultando necessidade precoce e permanente do tratamento com insulina e risco de cetoacidose, ou é de instalação mais lenta, em adultos, que podem reter a função residual das células-beta por até alguns anos após o diagnóstico. É uma das doenças crônicas mais comuns e graves da infância e da adolescência, sendo caracterizada pela presença de auto-anticorpos contra antígenos pancreáticos (1).

Difere do diabetes tipo 1 idiopático (tipo 1B) (1) e diabetes tipo 1 fulminante (2), que não têm etiologia auto-imune, e do diabetes duplo (LADY) (3), que tem interface com auto-imunidade e resistência à insulina.

\section{EPIDEMIOLOGIA DO DIABETES MELITO TIPO 1 AUTO-IMUNE}

O DMlA compreende $90 \%$ dos casos de diabetes da infầncia e $5 \%$ a $10 \%$ daqueles de início na idade adulta, visto que $40 \%$ do DMlA ocorre até os 20 anos de idade (4). Sua prevalência é inferior a $1 \%$. Predomina na raça branca, porém sua incidência é variável entre populações e áreas geográficas, refletindo diferentes genes de suscetibilidade e fatores ambientais desencadeantes. As maiores taxas de incidência mundial (superiores a 35/100.000/ano) ocorrem na Finlândia e na Sardenha (Itália), seguidas por populações caucasianas na Europa e na América do Norte, de incidência moderada (cerca de 10-20/100.000/ano). Finalmente, os países asiáticos e a grande maioria dos países da América do Sul apresentam as menores taxas mundiais (inferiores a 5/100.000/ ano). No Brasil, a incidência é de $8 / 100.000 /$ ano $(5,6)$. A incidência anual de DMlA está aumentando em 3,2\% nos mais jovens, principalmente naqueles manifestados antes dos 4 anos de idade, sugerindo fator ambiental atuante $(7,8)$.

A idade de diagnóstico do DMlA é mais freqüente entre 8 e 13 anos (8). Em pacientes de São Paulo (HCFMUSP), observamos idade de diagnóstico semelhante (Figura 1), e predomínio da raça branca: $81,2 \%$ brancos; $2,3 \%$ negros; $15,8 \%$ pardos e $0,6 \%$ asiáticos em 469 pacientes DMIA analisados (dados não publicados).
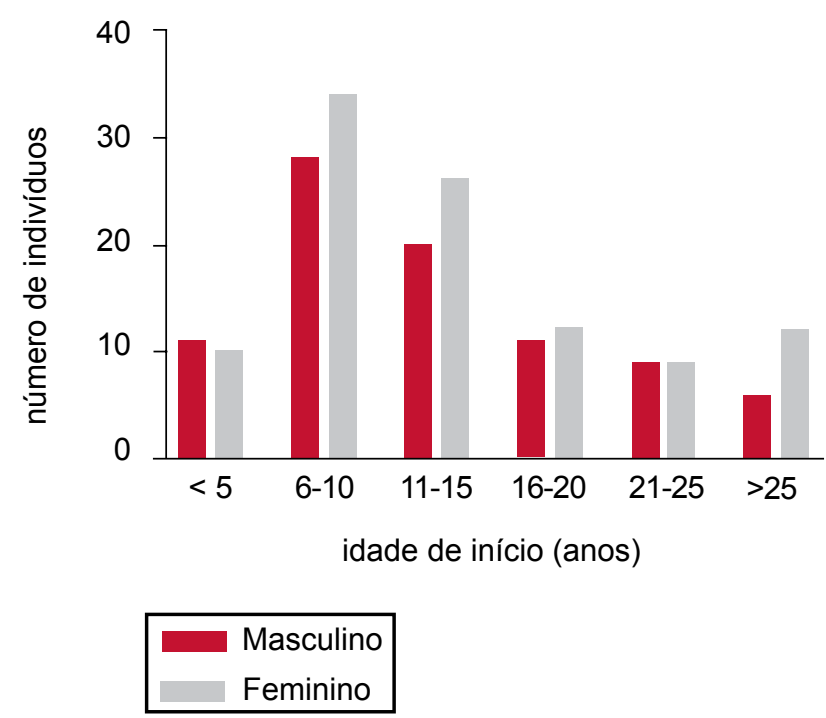

Davini e cols. (15).

Figura 1. Idade do diagnóstico do DM1A.

O DMIA incide igualmente nos sexos masculino e feminino, mas, nos países com alta prevalência da doença, predomina nos homens com diagnóstico após os 20 anos de idade (7). A agregação familiar é rara, mas superior à da população normal, sendo o risco para diabetes de $1,3 \%$ nos pais, $4,2 \%$ nos irmãos e $1,9 \%$ nos filhos dos diabéticos. A transmissão paterna do diabetes para os filhos é maior que a materna (5). Cerca de $10 \%$ a $13 \%$ dos pacientes com DMlA recém-diagnosticados têm um familiar de primeiro grau afetado.

A concordância entre gêmeos monozigóticos $(50 \%)$ difere acentuadamente da dos dizigóticos (5\%). A probabilidade de o gêmeo discordante desenvolver a doença diminui com a duração da discordância, mas pode ocorrer até 40 anos após. O risco para diabetes no gêmeo dizigótico é semelhante ao dos outros irmãos, sugerindo que o ambiente compartilhado pelos gêmeos dizigóticos não parece aumentar o risco de diabetes (8).

Tais dados epidemiológicos evidenciam a clara interação entre genética e ambiente.

\section{HISTÓRIA NATURAL DO DM1A}

\section{Suscetibilidade genética}

Múltiplos genes contribuem para o DMlA humano, que tem características fisiopatológicas e genéticas comuns com o do camundongo NOD (non obese diabetes). Foram descritos mais de vinte loci que conferem 
suscetibilidade ao DMIA, denominados IDDM, estando os mais importantes localizados nos cromossomos $6,11,1$ e $2(6,9-11)$.

\section{Sistema HLA (lócus IDDM1)}

Os genes do maior complexo de histocompatibilidade (MHC) conferem maior risco relativo para desenvolver DMlA - entre 3 e 50 para os principais genótipos de predisposição versus menor que 3 para outros genes (8), além de várias outras doenças auto-imunes $(4,12)$.

A região do sistema antígeno leucocitário humano (HLA), localizada no complexo principal de histocompatibilidade (MHC), situa-se em uma região que se estende por $3.600 \mathrm{kpb}$ no braço curto do cromossomo 6 (p21.3), e constitui o principal lócus de suscetibilidade para DMlA, denominado IDDMl (40\% a 50\% de risco genético para DM tipo 1). Cerca de $30 \%$ da população geral apresenta algum grau de predisposição genética, mas apenas $0,5 \%$ evolui para DMlA $(6,10)$.

A região $\mathrm{MHC}$, altamente polimórfica, compreende genes agrupados em classe I (teloméricos) e classe II (centroméricos), separados pelos genes classe III. As moléculas de classe I e II estão envolvidas com a apresentação de peptídeos patogênicos aos linfócitos $\mathrm{T}$ e a resposta imune adaptativa. Na região classe II estão também localizados genes que codificam diversas proteínas citosólicas, associadas ao transporte e ao processamento de antígenos (TAPl e TAP2). Já a região classe III é responsável por proteínas importantes na resposta imune, como a proteína do choque térmico (HSP70), o complemento (C2 e C4) e o fator de necrose tumoral (TNF) (Figura 2) $(6,10,13)$.
As moléculas de classe I do sistema HLA, expressas na maioria das células somáticas, estão relacionadas ao processamento e à apresentação de antígenos intracelulares. São compostas por duas cadeias polipeptídicas ligadas não covalentemente, codificadas pelos genes $\mathrm{A}, \mathrm{B}$ e C do cromossomo 6 (cadeia $\alpha$ ) e o gene do cromossomo 15 (cadeia $\beta 2$-microglobulina) $(6,10)$.

As moléculas de classe II do sistema HLA são expressas em um grupo de células do sistema imune, que incluem monócitos/macrófagos, células dendríticas, epiteliais tímicas, linfócitos $\mathrm{B}$ e linfócitos $\mathrm{T}$ ativados, $\mathrm{e}$ atuam no processamento e na apresentação de proteínas extracelulares. São compostas de duas cadeias polipeptídicas alfa e beta associadas não covalentemente, ambas codificadas por genes do MHC. Os segmentos aminoterminais alfa $\mathrm{l}$ e beta $\mathrm{l}$ interagem para formar a fenda de ligação peptídica. As proteínas extracelulares, capturadas pelas células apresentadoras de antígenos (APCs), são degradadas, e os peptídeos resultantes ligam-se às fendas de ligação peptídica das moléculas de classe II (Figura 3). Tais complexos serão reconhecidos como próprios ou não próprios pelos receptores dos linfócitos T (TCR), determinando a resposta imunológica a ser desenvolvida $(6,10)$.

No lócus HLA-DR, os alelos $-\mathrm{DR}^{*} 03$ ou $\mathrm{DR}{ }^{*} 04$ são os mais freqüentes nos pacientes diabéticos $(95 \%$ versus $50 \%$ dos controles caucasianos). Considerando-se que $30 \%$ a $40 \%$ desses pacientes, principalmente as crianças, são heterozigotos HLA-DR*03/DR*04 (versus $2 \%$ a $3 \%$ dos controles), esse genótipo confere o maior risco para a doença, seguido pela homozigose para $-\mathrm{DR}^{*} 04 \mathrm{e}$, finalmente, para $-\mathrm{DR}^{*} 03(6,10)$. Os alelos $\mathrm{DRB}{ }^{*} 0405$

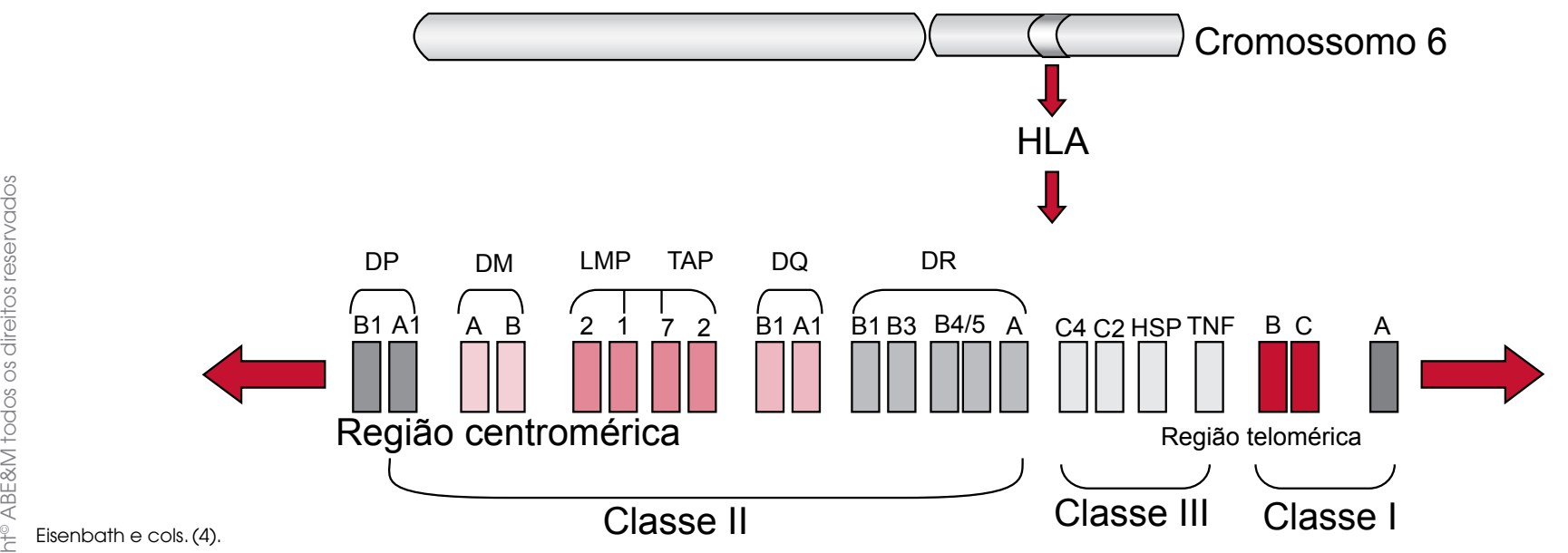

Figura 2. Estrutura gênica do MHC humano, identificando os genes HLA de classe I (HLA-A, B e C), de classe II (HLA-DR, DQ e DP) e os de classe III. Os genes TAP, LMP e HLA-DM codificam proteínas não expressas nas superfícies celulares. 


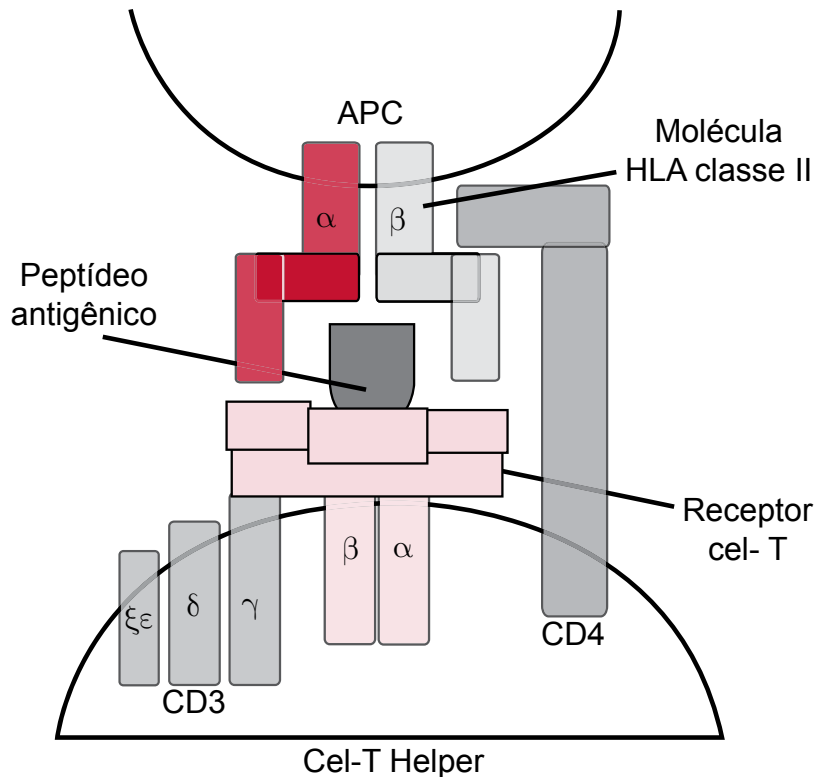

Figura 3. Interação do complexo da molécula HLA de classe II com peptídeo antigênico e o receptor da célula T.

e *0401 são de predisposição, os *0402 e *0404 são neutros e os *0403, *0406 e *0407 são protetores (6).

Há diferenças étnicas nessa predisposição genética. Assim, o efeito sinérgico HLA-DR*03/DR*04, evidenciado em caucasianos, não é observado na população japonesa, na qual os alelos $-\mathrm{DR}^{\star} 04,-\mathrm{DR}^{*} 08$ e $-\mathrm{DR}^{*} 09$ conferem a maior suscetibilidade $(9,13,14)$. Já os alelos -DRBI*15 e -DRBI*11 são considerados protetores para diabetes na maioria dos grupos étnicos $(6,10)$.

Quanto ao locus HLA-DQ, este codifica um heterodímero funcional altamente polimórfico, constituído de duas cadeias glicoprotéicas alfa e beta. O lócus -DQBI possui 42 alelos atualmente reconhecidos (6). Em caucasianos, os alelos -DQA1 *0301, $-\mathrm{DQB1} * 0302$ e -DQAl *0501, -DQBI*0201 são os mais importantes na suscetibilidade ao diabetes auto-imune e encontram-se em desequilíbrio de ligação com os alelos HLA-DR*04 e DR*03, respectivamente, os quais influenciam no risco determinado por aqueles alelos. Estudos relatam que a presença do ácido aspártico na posição 57 da cadeia DQ beta (Asp57+) oferece resistência ao diabetes, e a presença de outros aminoácidos nessa posição (Asp57-) está associada à suscetibilidade em inúmeras populações, exceto na japonesa, na qual a maioria dos alelos de suscetibilidade são Asp57 $7^{+}$, confirmando novamente que a freqüência alélica é variável conforme a origem étnica e a localização geográfica $(6,10)$.
Os loci DR e DQ são responsáveis por $40 \%$ a $50 \%$ do risco genético de desenvolver DMlA $(6,10)$. Como a região HLA exibe grande grau de desequilíbrio de ligação (ou seja, alelos DR e DQ não são associados randomicamente entre si), as associações do HLA com a doença são mais bem definidas pelos haplótipos do que pelos alelos. O maior risco é conferido pelos haplótipos de predisposição HLA-DQAl *0501-DQB1*0201 (chamado DQ2), geralmente herdado com DRB1 *0301(DR3) e o haplótipo $-\mathrm{DQAl}^{*} 0301-\mathrm{DQB1}{ }^{*} 0302$ (DQ8), herdado com $\mathrm{DRB1}{ }^{*} 0401$ ou DRB1*0405 (DR4). Os indivíduos heterozigotos DR3/DR4 ou DQ2/DQ8 têm risco absoluto de adquirir DMlA de $5 \%$ aos 15 anos de idade. O risco com esse genótipo aumenta para $20 \%$ em familiares de afetados, sugerindo efeito aditivo de outros genes ou influência ambiental (8).

Por outro lado, alguns haplótipos estão associados à proteção, particularmente HLA-DRBI*1501/ DQA1 *0102-DQB1 *0602 (DR2-DQ6), sendo o alelo *0602 o principal responsável pela proteção (presente em $20 \%$ dos controles versus $<1 \%$ em crianças diabéticas). Familiares de DMlA com esse alelo, mesmo com anticorpo antiilhota positivo, detêm baixo risco para a doença. Essa proteção, no entanto, não é absoluta, principalmente nos adultos $(6,8)$.

$\mathrm{O}$ mecanismo pelo qual o MHC atua na predisposição do DMlA não está completamente elucidado, mas possivelmente envolve o processo de deleção de clones de linfócitos auto-reativos no timo. O polimorfismo das moléculas de classe II parece interferir com sua ligação com o peptídeo antigênico e o receptor do linfócito $\mathrm{T}$ e determinar deleções mais ou menos efetivas desses linfócitos, conferindo resistência ou suscetibilidade para a doença, respectivamente $(6,10)$.

As moléculas HLA classe II, de suscetibilidade e proteção, ligam-se a diferentes epitopes dos antígenos, como GAD e insulina, e apresentam peptídeos distintos, que atuam estimulando ou inibindo a auto-imunidade. Alternativamente, moléculas de proteção poderiam atuar pelo estímulo da resposta imune reguladora (11).

Nos pacientes com DMlA no Hospital das Clínicas da FMUSP (São Paulo), Davini e cols. (15) observaram os seguintes haplótipos como determinantes dos maiores riscos relativos $(\mathrm{RR})$ para diabetes: HLA-DRB ${ }^{*} 03$ / $\mathrm{DQBI}{ }^{*} 0201$ em $45,2 \%$ (RR: 2,6) e -DRB1*04/ $\mathrm{DQB1}{ }^{*} 0302 \mathrm{em} 52,7 \%$ (RR 2,9) dos diabéticos versus $17,8 \%$ e $16,3 \%$ dos controles, respectivamente. Já os haplótipos -DRBI*11/DQB1*0301, -DRB1*13/ $\mathrm{DQBl}{ }^{*} 0602,-\mathrm{DRB}^{*} 13 / \mathrm{DQB}{ }^{*} 0603$ e $-\mathrm{DRB}{ }^{*} 15 /$ 
DQBI *0602 (RR 0,14) conferiram proteção, à semelhança das populações caucasianas. Os maiores riscos relativos foram conferidos pelos genótipos -DR3/DR4 em $23,6 \%$ (RR 6,7) e -DQBI *0201/*0302 em 20,9\% dos pacientes ( $R R 18,4$ ) versus $3,3 \%$ e $1,1 \%$ dos controles, respectivamente. Alves e cols. (16) analisaram cinco outros estudos sobre alelos e haplótipos HLA no Brasil, confirmando a maior suscetibilidade para os haplótipos DR3/DQ2 e DR4/DQ8 e para os alelos HLA classe I $-\mathrm{A} 2,-\mathrm{B} 8,-\mathrm{B} 13$ e $-\mathrm{B} 15$ e a proteção para alelos -DQB1 *0602 e -DQB1*0301, DR2 e DR7.

Essa associação entre alelos de classe I e II decorre em razão de a região MHC manter haplótipos altamente conservados e muitos haplótipos estendidos, contendo, por exemplo, os alelos HLA DR3 Al e B8, chamado haplótipo 8.1, ou os alelos DR3, A30 e B18, ou haplótipo Basque (4).

Nesses haplótipos altamente conservados, abrangendo longas distâncias genômicas, muitos alelos HLA classe I estão em desequilíbrio de ligação com $\mathrm{DR}$ e $\mathrm{DQ}$, mas alguns interferem também diretamente na suscetibilidade. Efeito independente na susceptibilidade foi verificado para alelos HLA- $B * 8,-B * 15,-B * 39,-B * 18,-A * 24$, enquanto HLA-B*27, $-A^{*} 01,-A^{*} 11$ foram protetores. A importância de moléculas classe I reside em sua interação com linfócitos T CD8+, que são as principais células que infiltram as ilhotas, e no fato de as próprias células das ilhotas expressarem moléculas MHC classe I $(6,17)$.

Ainda na região HLA há o gene MICA (MHC class I chain-related gene-A) (Figura 2), no cromossomo 6, centromérico ao HLA-B, que codifica a proteína que ativa células NK e células $\mathrm{T}$. O polimorfismo no número variável de repetições GCT(Ala) no exon da região transmembrana determina sete variantes alélicas. A maior freqüência de variantes MICA 5.0 e 5.1 predispõe a DMlA de início tardio, doença de Addison e formação de auto-anticorpos $(6,12,18)$.

\section{INS-VNTR (lócus IDDM2)}

$\mathrm{O}$ segundo maior lócus de susceptibilidade para o DM1A, denominado IDDM2, situa-se na região 5' do gene da insulina (INS), no cromossomo $1 \mathrm{lpl}$, em uma região de $4,1 \mathrm{~kb}$ que abrange o gene da insulina, o da tirosina hidroxilase, o do fator de crescimento insulina-símile IGF-2 $(9,19)$ e contribui com $10 \%$ da suscetibilidade genética para a doença (Figura 4). A maior associação com DMl foi definida para a região minissatélite não transcrita, altamente polimórfica, números variáveis de repetições consecutivas (VNTR), composta de 14 a 15 pares de base de oligonucleotídeos que se repetem (seqüência consenso: ACAGGGGTGTGGGG) (19). Compreende três classes de alelos de acordo com seu tamanho, determinado pelo número de repetições: 26-63 repetições (alelos de classe I), 140-200 repetições (alelos de classe III), sendo os alelos de classe II, intermediários, extremamente raros $(6,8-10,19)$.

A freqüência desses alelos difere entre grupos raciais. Undlien e cols. (20) demonstraram que os alelos de classe I conferiam suscetibilidade ao DMlA na população caucasiana, e não nos negros e japoneses. A presença dos

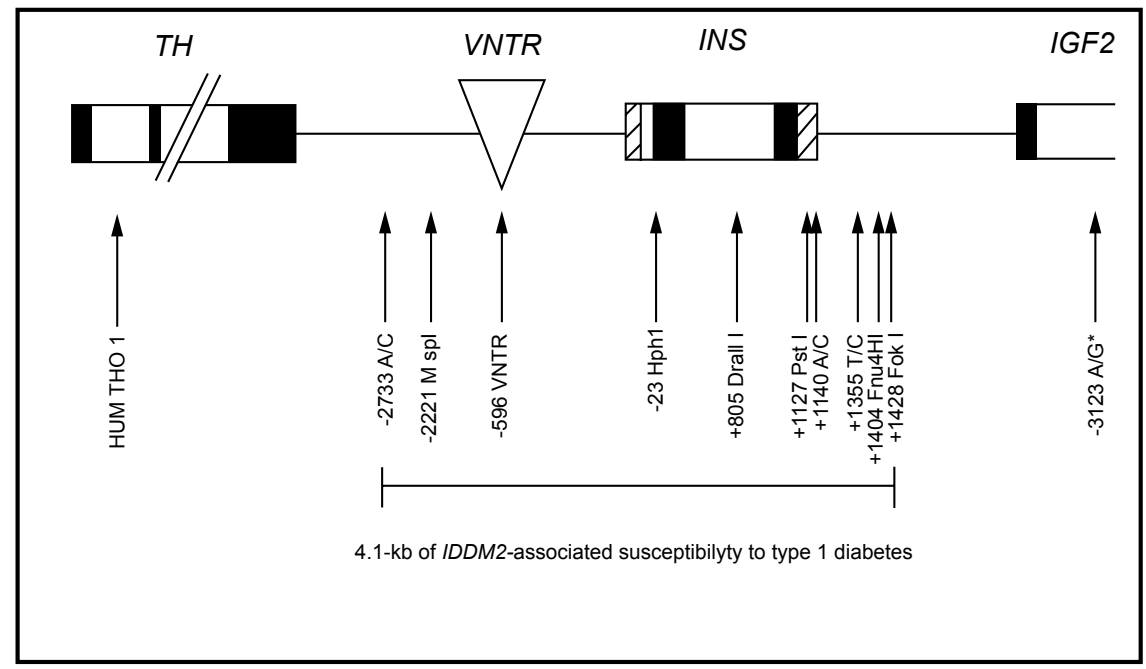

Figura 4. Região TH-INS-IGF2 no cromossomo 11 p15.5. 
genótipos I/I varia de $30 \%$ a $61 \%$ nos controles normais, e na população diabética caucasiana é geralmente superior a $60 \%$, conferindo risco relativo de 1,9 a 3,5 (19). Há dois estudos em São Paulo. Para Davini; e cols. (15) (FMUSP - 187 diabéticos e 195 controles), o genótipo INS VNTR I/I (avaliado pelo polimorfismo INS - 23 A/T) prevaleceu nos pacientes diabéticos $(60,4 \%) \mathrm{em}$ relação à população controle $(27,2 \%)$, conferindo risco relativo para DMlA de 2,2. Já Hauache e cols. (21) (Unifesp - 126 diabéticos e 75 controles normais) observaram o genótipo -2221CC do gene da insulina (polimorfismo -2221C/T) em 83,1\% dos diabéticos e 69,3\% dos controles (OR 1,98).

Os alelos de classe III, considerados protetores, estão associados à redução de $60 \%$ a $70 \%$ no risco de desenvolver DMIA $(6,10)$. Condicionam, no timo, níveis mais elevados de RNAm da insulina (2 a 3 vezes) e da proteína pré-pró-insulina, a qual é um antígeno-chave na patogênese do diabetes. A maior transcrição tímica de insulina modulada pelos alelos de classe III aumenta a probabilidade de seleção negativa das células $\mathrm{T}$ tímicas auto-reativas, conferindo melhor tolerância imune nos indivíduos portadores desses alelos.

O polimorfismo do INS-VNTR não parece determinar suscetibilidade para outras doenças auto-imunes $(6,22)$.

\section{CTLA-4 (lócus IDDM12)}

Outra região relacionada ao DMl está localizada no cromossomo $2 \mathrm{q} 33$ e contém os genes das moléculas CTLA-4, CD28 e ICOS, em desequilíbrio de ligação, mas a associação foi confirmada para o gene CTLA-4 (lócus IDDMI2) $(6,8,9)$.

$\mathrm{O}$ antígeno 4 associado ao linfócito $\mathrm{T}$ citotóxico (CTLA4) é uma molécula de superfície celular da superfamília das imunoglobulinas. Expressa-se em linfócitos $\mathrm{T}$ CD4+ e CD8+ ativados e liga-se às moléculas B7-1 e B7-2 das células apresentadoras do antígeno (APC), inibindo a ativação das células $\mathrm{B}$ e $\mathrm{T}$, a proliferação das células $\mathrm{T}$, a produção de citocinas e de imunoglobulinas (Figura 5) $(6,8,9)$.

Inúmeros polimorfismos do gene CTLA4 têm sido associados ao DMlA, mas com resultados conflitantes, em pequenos números amostrais. Entre eles está o microsatélite (AT)n 3'UTR (região não transcrita), na posição 642 do exon 4; o polimorfismo A/G - (Thr/Ala) na posição 49 do exon l (A49G); o polimorfismo C/T na posição 318 da região promotora; os polimorfismos + $6230 \mathrm{G}>\mathrm{A}, \mathrm{MH} 30$, Jo30 e rs1863800, associados principalmente às doenças tireoidianas auto-imunes $(6,8-9,23)$.

A correlação do polimorfismo A49G do CTLA-4 com DMl foi exaustivamente estudada em populações

\section{Interações entre a APC e o linfócito T}

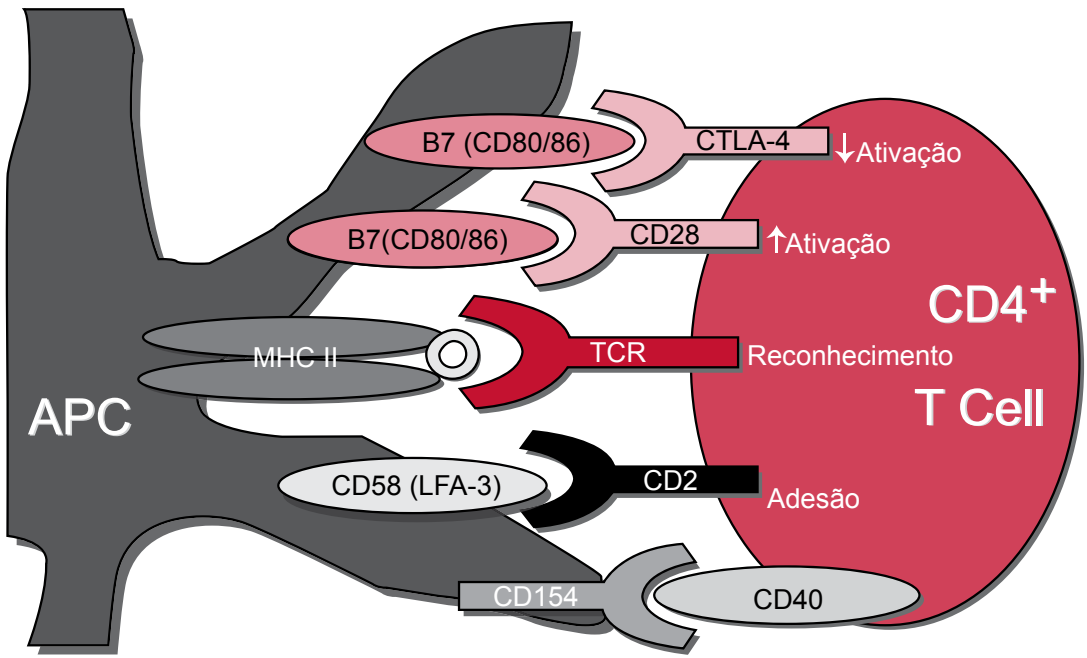

APC = célula apresentadora do antígeno.

Figura 5. Inibição da ativação do linfócito T CD4+ pelo CTLA-4. 
de diferentes regiões, sendo evidenciada nos estudos realizados na Espanha, na Itália, na França, na China, na Coréia, no Marrocos, na Bélgica, no Japão e em populações americanas-mexicanas. $\mathrm{O}$ mesmo não foi observado em famílias na Inglaterra, na Alemanha e na Checoslováquia. A associação com a doença parece depender da distribuição do alelo na população estudada e da incidência da doença. O polimorfismo A49G também foi associado a outras doenças auto-imunes, como o hipotireoidismo, a doença celíaca, a artrite reumatóide, a miastenia gravis, a esclerose múltipla e a doença de Addison $(12,23,24)$.

Ueda e cols. (25) relacionaram o polimorfismo A6230G na 3'UTR ao DMl e à maior expressão do transcrito alternativo do CTLA4 que codifica uma forma solúvel da proteína. Esses dados não foram replicados e há também resultados contrastantes $(9)$.

Recentemente Ikegami e cols. (23) analisaram 1.114 pacientes $(769$ com diabetes e 345 com doença tiroidiana auto-imune) e 723 controles, e evidenciaram que os polimorfismos A49G e A6230G (também designado CT60 ou alelo rs3087243) estão associados à doença tireoidiana auto-imune e não ao diabetes. A relação com diabetes parece se dever à alta prevalência de doença tireoidiana na população diabética.

Em São Paulo, FMUSP, Gamberini e cols. (26), em estudo preliminar, não verificaram associação de dois polimorfismos: A49G e -318C/T (no exon 1 -região promotora) com DMl, em 279 pacientes e 151 controles normais Hauache e cols. (Unifesp) (21) também não observaram influência do polimorfismo $+49 \mathrm{~A} / \mathrm{G}$ em 126 diabéticos e 75 controles normais.

São ainda necessários estudos para definir melhor a variante causal.

\section{PTPN22}

O gene da Protein Tyrosine Phosphatase, non receptor 22 (PTPN22), no cromossomo lpl3, codifica a proteína tirosina fosfatase, que é expressa primariamente nos tecidos linfóides, também chamada Lymphoid Tyrosine Phosphatase (Lyp). Lyp é uma proteína intracelular que interage com a quinase reguladora negativa Csk, formando um complexo que inibe a ativação de células T (27).

Estudos funcionais indicam que a ligação à Csk está alterada na variante $\mathrm{C} 1858 \mathrm{~T}$, favorecendo a ativação imune $(6,8,9)$. Alternativamente, a variante Lyp pode afetar a população de células $\mathrm{T}$ reguladoras, tornandoas menos efetivas na supressão da resposta imune (9).
Esse polimorfismo confere suscetibilidade ao DMl em várias populações $(6,10,28)$. Seu efeito parece ser independente do HLA ou do genótipo de risco VNTR I/I do gene da insulina, estando ainda relacionado à presença persistente do anticorpo anti-GAD65 em pacientes com duração do diabetes superior a 10 anos (29). Confere suscetibilidade a outras doenças auto-imunes órgão-específicas e sistêmicas como artrite reumatóide, lúpus eritematoso sistêmico, tiroidite de Hashimoto e doença de Graves $(6,28)$.

Estudo em São Paulo (FMUSP) encontrou associação entre o polimorfismo R620W e DMl. Os genótipos TT e CT, presentes em 17,9\% dos indivíduos com DMl e $9,5 \%$ dos controles, foram associados ao aumento do risco de desenvolver DMIA (OR 2.069) o genótipo $\mathrm{C} / \mathrm{C}$ foi protetor $(\mathrm{OR} 0,5)(30)$.

\section{SUMO4 (lócus IDDM5)}

Na região genômica do lócus IDDM5, cromossomo 6q25, o polimorfismo $163 \mathrm{~A}>\mathrm{G}$ no domínio CUE do gene SUMO4 (small ubiquitin-like modifier type 4 protein), com troca do aminoácido metionina por valina $(\mathrm{M} 55 \mathrm{~V})$, tem alta associação com DMlA, doença tiroidiana auto-imune e artrite reumatóide em coreanos e japoneses, mas os resultados são ainda inconsistentes nos caucasianos. Parece que SUMO4 causa modificação covalente reversível de proteínas (sumoilação), estando associado à manutenção da homeostase celular e à defesa diante de estresse e insultos inflamatórios. SUMO4 liga-se a IkBa e inibe a transcrição de NFkB (fator nuclear kappa beta). A substituição de um aminoácido na proteína SUMO4 aumenta a atividade transcricional de NFkB, envolvida na patogênese da auto-imunidade e na formação de radicais livres. Há quatro genes SUMO, sendo os genes 1, 2 e 3 difusamente distribuídos no organismo. Já o SUMO 4 é expresso em tecidos imunes, rins e pâncreas $(6,11)$.

\section{NEUROD1 (loci IDDM7, IDDM12 e IDDM13)}

O gene NEURODl, cromossomo 2q31-35, correspondente aos loci de suscetibilidade IDDM7, IDDM12 e IDDM13, codifica um fator de transcrição para o gene da insulina expresso no pâncreas e está envolvido no desenvolvimento das ilhotas pancreáticas (6). Mutações nesse gene estão associadas ao MODY 6. Oliveira e cols. (31) em estudo em São Paulo (Unifesp) observaram associação do alelo Thr da variante Ala45Thr no exon 2 do gene NEURODl com o DMl em mulheres. 
No entanto, em estudo de metanálise não foi confirmada essa associação (32).

\section{Receptor da Vitamina D (VDR)}

A vitamina $\mathrm{D}$ é reconhecida por sua ação imunomoduladora. A 1,25 dihidroxivitamina $\mathrm{D}_{3}$ estimula a fagocitose e a morte de bactérias e reduz a capacidade de apresentação de antígenos pelas células dendríticas in vitro e a produção de citocinas (33).

Seu receptor é encontrado nos macrófagos, células apresentadoras de antígeno e linfócitos T ativados. Os polimorfismos do gene do receptor da vitamina $\mathrm{D}$ também têm sido estudados como marcadores da suscetibilidade genética do DMIA, com resultados diversos $(34,35)$. Os polimorfismos FokI e BsmI do VDR foram avaliados em 189 indivíduos com DMIA acompanhados no Centro de Diabetes/Unifesp (São Paulo). Mory e cols. (36) observaram maior freqüência do polimorfismo Bsm I em homo ou heterozigose no grupo controle em relação ao grupo com $\mathrm{DMl}(79,2 \%$ versus $66,1 \%$ ). Não houve diferença para o polimorfismo FokI. Nos indivíduos com DMlA houve tendência a menor função residual da células-beta, avaliada pela dosagem do peptídeo-C de jejum, presença do polimorfismo Fok I e tendência a maiores níveis de peptídeo-C de jejum na presença do polimorfismo BsmI. Os resultados sugerem uma relação heterogênea entre os polimorfismos estudados e a secreção de insulina nos indivíduos com DMl, sendo positiva com o BsmI e negativa com o FokI na população avaliada.

Novas associações genéticas ainda requerem confirmação, como as da região IFIHl, no cromossomo 2q, do receptor da interleucina-2 (IL2RA), da Il-12, do ITPR3 (inositol trifosfato receptor 3), KIAA0350, ICAM, RANTES, PD-1, KI e vários fatores de transcrição e citocinas relacionadas com a resposta imune $(4,6,8,9,11)$.

Inúmeros genes candidatos têm sido relacionados ao DMlA, e muitas das associações não se repetiram em estudos independentes. Outras foram confirmadas de maneira não consistente, e apenas algumas associações o foram de maneira inequívoca, sendo estabelecidas como fatores de risco para DMlA. Compreendem, além do HLA, o minissatélite VNTR do gene da insulina e o PTPN22.

Os estudos genéticos são complicados pela heterogenidade de diferentes populações e grupos étnicos. Dados de caucasianos nem sempre se aplicam a outras etnias. Há ainda a heteregeneidade de ligação. A contribuição de um gene varia com o desequilíbrio de ligação e interação com outros genes, que podem diferir entre as populações. Variantes que conferem pequeno risco para a doença podem induzir alterações no gene candidato, contribuindo para a destruição auto-imune, embora não sejam o fator causal. Interações gene-ambiente são complicadores adicionais.

Outros fatores, como metilação do DNA, modificação pós-translacional de proteínas por fosforilação, acetilação e ubiquitinação, são mecanismos que regulam vários processos biológicos e atuam na expressão dos genes, favorecendo ou reprimindo os processos imunes (11).

Diante de todas essas dificuldades, estudos multicêntricos com centenas de famílias são fundamentais para definir o papel dos genes na suscetibilidade ao DMIA. Neste sentido, os genome-wide association studies, testando 500.000 SNPs no genoma, o Wellcome Trust Case Control Consortion genome-wide association scan e o multiple autoimmune disease genetics consortium (MADGC) avaliam, em múltiplos grupos, regiões cromossômicas implicadas à auto-imunidade (9).

\section{Fatores desencadeantes}

Vários agentes etiológicos foram apontados como desencadeantes da auto-imunidade. Entre eles temos os vírus Coxsackie e da rubéola, as toxinas (pesticidas, ntratos), o reduzido número de infecções (teoria da higiene), a deficiência na suplementação de vitamina $\mathrm{D}$ e alguns alimentos (introdução precoce do leite de vaca ou tardia e abrupta de cereais) $(6,8,37)$.

\section{Auto-imunidade ativa}

O DMIA tem início quando ocorre um desequilíbrio nos mecanismos de tolerância aos antígenos próprios, resultando insulite: infiltrado inflamatório composto de linfócitos T e B, macrófagos e células dendríticas. As células T-CD4 ativadas (CD4+) agem no processo da insulite, determinando reações inflamatórias e secreção de citoquinas, especialmente interleucina 1 (IL-1), interferon $\gamma($ IFN- $\gamma)$ e fator de necrose tumoral alfa (TNF- $\alpha$ ), culminando com a morte das células-beta (imunidade celular). As células T CD4+ também funcionam como células auxiliares ativadoras das células T-CD8 e linfócitos B produtores de auto-anticorpos (imunidade humoral) (6) (Figura 6). 


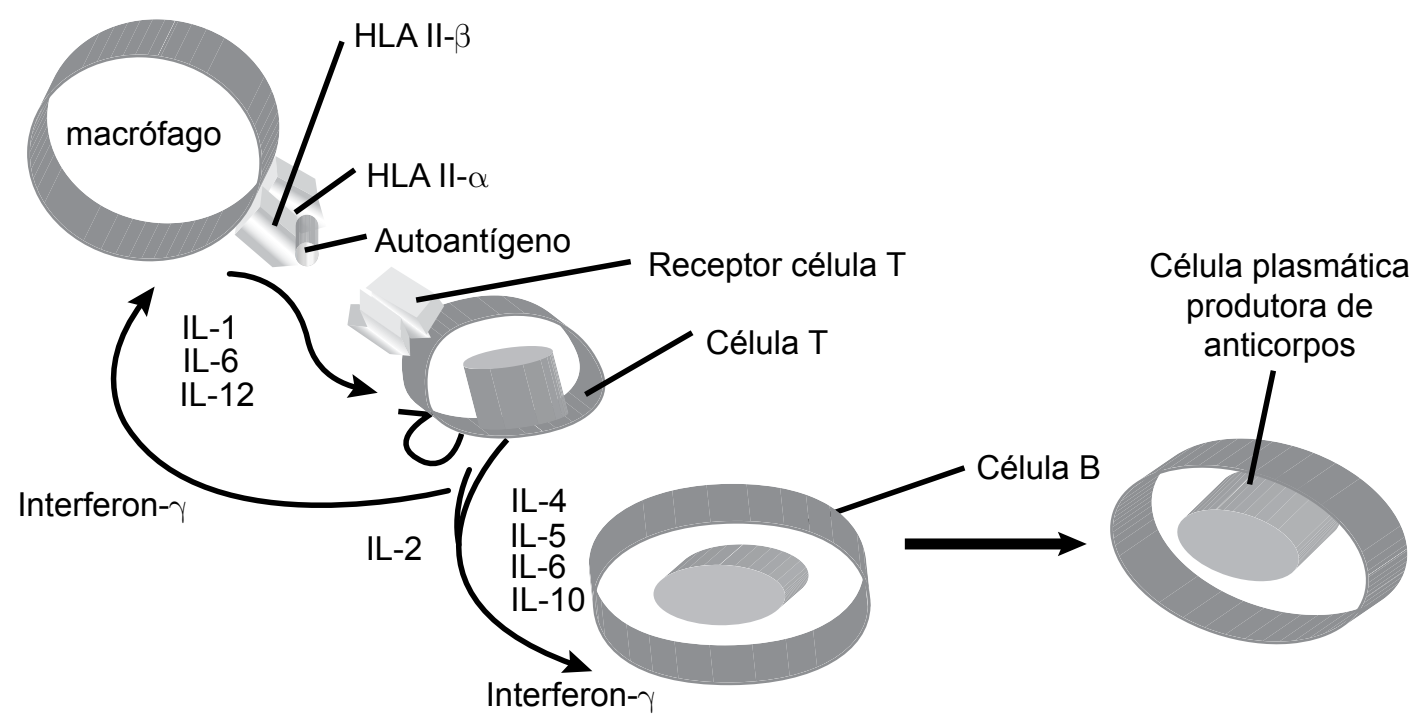

Figura 6. Resposta auto-imune adaptativa.

O período de auto-imunidade ativa, conhecido como pré-diabético assintomático ou fase subclínica, precede o diabetes e pode ter duração de vários anos, sendo evidenciado pela presença de auto-anticorpos contra antígenos das células-beta e pela perda progressiva da capacidade secretora de insulina. Ao diagnóstico do DMlA, restam apenas $10 \%$ das células-beta e, com o passar do tempo, estas tornam-se virtualmente ausentes. As demais células das ilhotas pancreáticas não são atingidas, e persistem produzindo glucagon (células-alfa) e somatostatina (célulasdelta). A secreção de glucagon aumenta pela perda do efeito supressor da insulina. A deficiência de insulina pode ainda causar certa atrofia do pâncreas exócrino e redução das enzimas pancreáticas (6).

$\mathrm{O}$ antígeno específico da célula-beta, alvo inicial do sistema imune, não está definido, mas os auto-anticorpos contra vários componentes das células-beta, presentes no soro de pacientes diabéticos recém-diagnosticados $\mathrm{e}$ de indivíduos que posteriormente desenvolvem a doença, são importantes marcadores da progressão dela $(6,7,38)$. Recentemente, novo e importante antígeno foi identificado no camundongo NOD, o IGRP (isletspecific glucose-6-phosphatase catalytic subunit-related protein), que está sendo avaliado no homem (11).

A produção de anticorpos pelos linfócitos $\mathrm{B}$ não parece ser apenas secundária à destruição das célulasbeta e ao estímulo pelos linfócitos T. As células-beta também agem como apresentadoras de antígeno, necessárias à expansão eficiente de células T-CD4+ autoreativas diabetogênicas. Assim, no DMlA, além da perda da tolerância pelas células $\mathrm{T}$, há também perda da tolerância pelas células $\mathrm{B}$, que expressam imunoglobulinas auto-reativas. A presença de auto-anticorpos contra vários tecidos no DMIA pode ser resultado dessa alteração.

Os marcadores humorais mais freqüentes da agressão imune são os anticorpos antiinsulina (IAA), antiilhotas de Langerhans citoplasmático (ICA), antienzima descarboxilase do ácido glutâmico 65 (anti-GAD65) e antiproteína de membrana com homologia às tirosinofosfatases ou antiantígeno 2 do insulinoma (anti-IA2). A freqüência desses auto-anticorpos no DMlA encontra-se na Tabela 1 . Os auto-anticorpos são raros na população controle não-diabética - freqüência de $2 \%$ a $5 \%$ $(6,7,38)$.

ICA é um anticorpo da classe IgG, policlonal. O ICA não é dirigido contra um antígeno específico das células-beta, mas a uma ou várias estruturas celulares ao mesmo tempo (GAD65, IA2 e outros antígenos).

O IAA predomina nas crianças, particularmente nas do sexo masculino, sendo menos freqüente em adultos, em que tem baixa sensibilidade diagnóstica (10\%). É também encontrado no soro de pacientes em uso de insulina (7 a 10 dias após o início do tratamento) e, nestes casos, não serve como marcador $(6,7,38)$.

Anti-GAD65 é freqüentemente associado a outras doenças auto-imunes além do diabetes, e sua presença não necessariamente implica progressão rápida para doença. Mantém sensibilidade de $70 \%$ a $80 \%$ para o diagnóstico de diabetes auto-imune, independentemente da idade (7). 
Tabela 1. Freqüência dos auto-anticorpos.

\begin{tabular}{|c|c|c|c|}
\hline \multirow[t]{2}{*}{ Auto-Anticorpos } & \multicolumn{3}{|c|}{ Idade } \\
\hline & $0-9$ anos & 10-19 anos & 20-39 anos \\
\hline IAA & $78 \%$ & $43 \%$ & $29 \%$ \\
\hline ICA & $86 \%$ & $84 \%$ & $60 \%$ \\
\hline Anti-GAD 65 & $64 \%$ & $80 \%$ & $78 \%$ \\
\hline IAA ou ICA & $91 \%$ & $92 \%$ & $65 \%$ \\
\hline \multirow[t]{2}{*}{ IAA ou ICA ou anti-GAD } & $91 \%$ & $98 \%$ & $85 \%$ \\
\hline & $<15$ anos & $20-40$ anos & $>40$ anos \\
\hline Anti-IA2 & $86 \%$ & $45 \%$ & $<30 \%$ \\
\hline
\end{tabular}

ICA - anticorpo antiilhota de Langerhans; IAA - anticorpo antiinsulina; anti-GAD65 - anticorpo antidescarboxilase do ácido glutâmico 65; anti-IA2 - anticorpo antitirosina fosfatase $(6,39)$

$\mathrm{O}$ anticorpo anti-IA2 é mais comum entre indivíduos jovens (até 15 anos de idade) e indica rápida progressão para o diabetes manifesto $(6,7,38)$. Diferentes isoformas do IA-2 no timo e no baço, comparadas à do pâncreas, podem induzir auto-imunidade à seqüência IA-2 não-presente nos tecidos linfóides (11).

Os auto-anticorpos, em altos títulos ao diagnóstico, tendem a desaparecer com o tempo, à exceção do anti-GAD65. Davini e cols. (15), no HC-FMUSP, observaram altos títulos e maior freqüência de auto-anticorpos (2-3 auto-anticorpos positivos) nos primeiros cinco anos de duração da doença (Figura 7). Já os títulos de anti-GAD 65 se mantiveram mais constantes com a progressão da doença. Anti-IA2 predominou nos portadores dos alelos DRB1*04 e DQB1 ${ }^{*} 0302$.

\section{HISTÓRIA NATURAL DOS AUTO-ANTICORPOS}

$\mathrm{O}$ reconhecimento dos genes de suscetibilidade e a identificação dos auto-anticorpos foram fundamentais na identificação de grupos de risco para o diabetes.

Estudos prospectivos, a partir do nascimento, em crianças com risco genético para DMlA ou filhos de pais com DMlA, também trouxeram grande contribuição ao conhecimento da patogênese do diabetes na infância, mapeando os eventos na fase pré-clínica. Tais estudos (TEDDY, BABYDIAB, DIPP, DAISY, PANDA) têm acompanhado a evolução dos auto-anticorpos e do diabetes $(6,7,38)$.

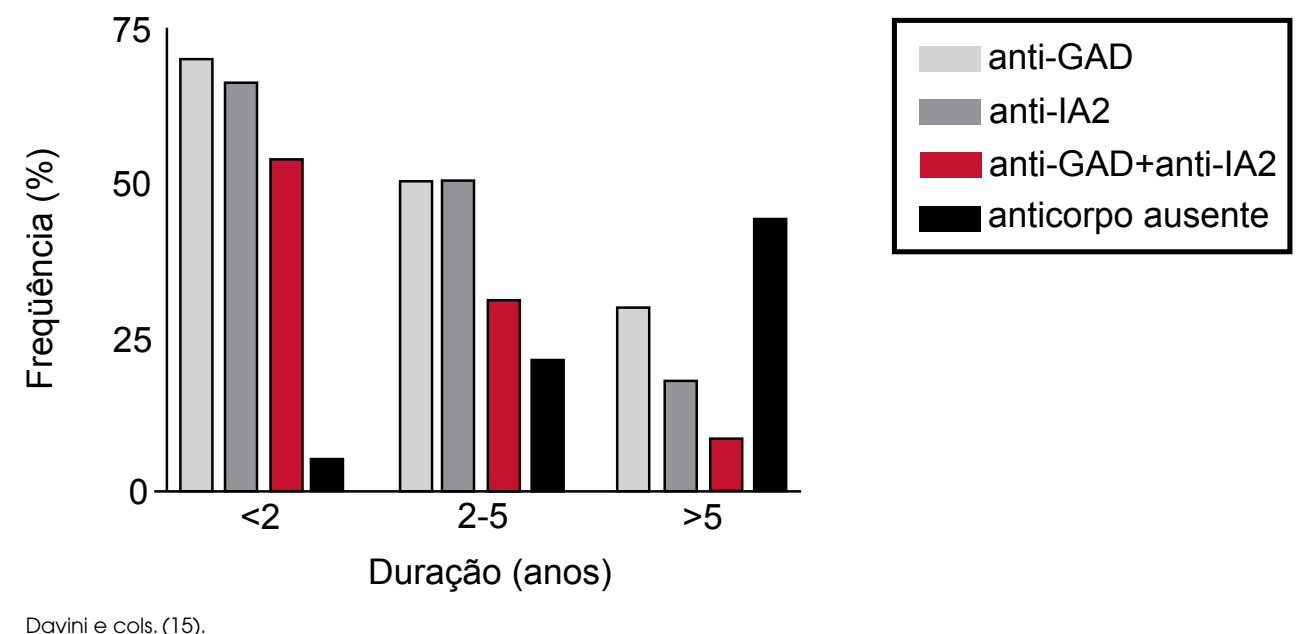

Figura 7. Freqüência dos auto-anticorpos, segundo a duração do diabetes. 
Crianças que desenvolvem DMIA até os 10 anos de idade apresentam os sinais de auto-imunidade precocemente até os 2 anos de idade, com rápida progressão para múltiplos auto-anticorpos. Correspondem a $4 \%$ dos filhos de pais com DMlA e 6\% das crianças com HLA de alto risco. Aquelas que desenvolvem auto-anticorpos mais tardiamente têm evolução mais lenta para múltiplos anticorpos e diabetes, e menor freqüência de IAA.

IAA é o primeiro auto-anticorpo. O IAA associado à progressão para $\mathrm{DMl}$ é um anticorpo tipo $\mathrm{IgGl}$, de alta afinidade (que reconhece epitopes da insulina e pró-insulina), que geralmente aparece concomitante ao anti-GAD65, seguido de anti-IA2 e anti-IA-2 $\beta$. IAA de baixa afinidade não se liga à pró-insulina e raramente é seguido por múltiplos anticorpos (38).

A expansão da auto-imunidade ocorre também em relação aos antígenos individualmente. $\mathrm{O}$ anti-GAD65 dirige-se, inicialmente, contra a porção média (resíduos 234-444) e COOH terminal (resíduos 440-585) da molécula e é conformacional, indicando a disseminação da reatividade ou imunização simultânea contra dois epitopes. Reatividade para a porção NH2 (amino) terminal, reconhecendo epitopes lineares, é rara em crianças e, quando ocorre, é tardia e fraca, de baixo valor prognóstico, assim como a reatividade para o GAD-67.

Reatividade inicial contra IA2 é heterogênea, contra os domínios nas regiões justamembrana, e a região média e $\mathrm{COOH}$ terminal do domínio da proteína tirosina fosfatase, estende-se tardiamente para anti-IA2 $\beta$.

O maior risco para progressão o DMlA é visto nas crianças portadoras de IAA em altos títulos e anti-IA-2, principalmente naquelas com anti-IA2 $\beta$ concomitante (38).

A seroconversão de crianças para auto-anticorpos positivos pode ocorrer após os 6 meses de idade. Há grande flutuação nos títulos de auto-anticorpos, e nem sempre persistem, principalmente naqueles em baixos títulos ou com genótipos de proteção. Parte desses anticorpos, quando transmitidos pela mãe diabética, podem permanecer por até 1 ano (IAA) ou 18 meses (antiGAD65) na criança. Cerca de $86 \%$ e $66 \%$ dos filhos de mães diabéticas têm IAA e anti-GAD65 e/ou anti-IA2, respectivamente, e a presença desses anticorpos parece estar associada ao menor risco de desenvolver diabetes nos filhos das mães em relação aos pais diabéticos (38).

Anti-GAD65 é mais freqüente em pacientes HLA DR3-DQ2, e IAA, ICA e IA-2 A em HLA-DR4-DQ8 e MICA5. O genótipo I/I do INS-VNTR também favorece IAA $(6,7,12,38)$.
Os auto-anticorpos, quando identificados no soro de indivíduos normais, predizem aqueles que irão desenvolver a doença e são úteis no diagnóstico precoce de DMlA. A presença de auto-anticorpos relaciona-se à menor produção de insulina, medida no GTT EV, e evolução para diabetes após 5 a 8 anos do início do processo de agressão $(6,7,38)$.

No Diabetes Prevention Trial-1 (DPT-1), o risco dos familiares de DMl progredirem para DMlA decorridos $\mathbf{5}$ anos foi de $80 \%$, e $\mathbf{1 0 0 \%}$ para os portadores de 2 e 3 auto-anticorpos, respectivamente (7). A velocidade de destruição das células-beta está relacionada à quantidade e ao tipo de auto-anticorpos positivos e marcadores genéticos de suscetibilidade.

Alves e cols. em São Paulo (HC-FMUSP) (dados não publicados) analisaram 542 familiares de primeiro grau de 148 pacientes DMlA, assim distribuídos: 247 irmãos, 242 pais e 53 filhos. Obtiveram a seguinte distribuição de auto-anticorpos: IAA $(6,2 \%)$, ICA $(8,8 \%)$, antiGAD65 $(4,0 \%)$ e anti-IA2 $(1,1 \%)$. Apenas 9 familiares tinham 2 ou mais anticorpos (2 pais, 1 filho e 6 irmãos). Em um seguimento de 5 anos, muitos desses anticorpos tornaram-se negativos, e 6 irmãos evoluíram para diabetes ( 7 deles com 3 ou 4 auto-anticorpos). Considerandose outros 4 irmãos já com diabetes e não incluídos nessa avaliação, a concordância entre irmãos foi de $4 \%$.

Kasse e cols. (Unifesp) (40) observaram ICA e IAA positivos em $5,6 \%$ e $18,7 \%$, respectivamente, dos familiares de primeiro grau de pacientes com DMlA.

Imunossupressores ou imunomoduladores estão sendo testados na prevenção do DMl em familiares portadores de auto-anticorpos com risco de desenvolverem a doença, particularmente crianças com 2 ou mais anticorpos persistentes e em títulos elevados.

\section{APLICAÇÃO CLÍNICA DA DETERMINAÇÃO DOS AUTO-ANTICORPOS E DOS GENES DE SUSCETIBILIDADE PARA O DIABETES}

\section{Definição da patogênese e prevenção do DM1A}

O conhecimento dos genes de suscetibilidade e a identificação dos auto-anticorpos tiveram sua maior aplicabilidade no estudo da patogênese do diabetes, no delineamento da história natural da doença e na identificação de grupos de risco. Os genes de suscetibilidade são muito difundidos na população não-diabética $47,2 \%$ tem o genótipo de risco DR3 ou DR4 em nosso 
meio (15), e não são suficientes para desencadear o diabetes - e respondem por $50 \%$ apenas do risco de desenvolver DMlA. Alelos de proteção, particularmente HLA-DQBI *0602, não o fazem de maneira absoluta. A presença de auto-anticorpos tem maior valor preditivo. No entanto, a progressão para diabetes nos portadores de auto-anticorpos poderá ser lenta ou acelerada, ou pode mesmo não ocorrer, dependendo da influência genética. Juntos, os determinantes genéticos e imunológicos, predizem o risco da doença e a indicação de prevenção. No entanto, como ainda não dispomos de terapia eficaz, tais avaliações estão restritas a centros de estudo e pesquisa. A determinação de auto-anticorpos, particularmente anti-GAD65 e anti-IA2, de fácil realização e reprodutibilidade, pode auxiliar no diagnóstico precoce e na prevenção de episódios de cetoacidose em familiares de diabéticos, mas não é indicação usual.

\section{Diagnóstico etiológico do diabetes}

Até alguns anos atrás, o diagnóstico de DMlA era fundamentado no quadro clínico, particularmente na idade de início - na infância e na adolescência. Com o aprimoramento das ferramentas diagnósticas, identificação de genes de predisposição e auto-anticorpos, evidenciaramse outros tipos de diabetes que incidem no jovem, que não têm envolvimento auto-imune e podem ter terapias distintas, incluindo o MODY, o diabetes mitocondrial, o diabetes neonatal com alteração no receptor SUR, o diabetes tipo $1 \mathrm{~B}$ e o diabetes fulminante $(1,2)$.

As mudanças no estilo de vida, a obesidade e o sedentarismo estão relacionados ao crescente aparecimento de diabetes melito tipo 2 (DM2) e ao diabetes duplo LADY (3), que tem interface com auto-imunidade e resistência à insulina. As dosagens dos auto-anticorpos auxiliam na definição desses quadros

Outra importante indicação destas determinações está na identificação dos portadores do diabetes latente auto-imune do adulto (LADA). Compreende o diabetes auto-imune que se manifesta mais tardiamente, após os 35 anos de idade, caracterizado por longo período prodrômico assintomático, ausência de sintomas agudos ou cetonúria ao diagnóstico e preservação de função residual das células-beta, que evolui para dependência de insulina decorridos até 5 anos do diagnóstico, simulando muitas vezes o DM2. Dados epidemiológicos demonstram que esse tipo de diabetes é responsável por $10 \%$ de todos os casos de diabetes. O diagnóstico é sugerido pelo quadro clínico: pacientes jovens, sem história familiar de DM2 e com menor freqüência dos compo- nentes da síndrome plurimetabólica. Apresentam genes de suscetibilidade para DMIA e outras auto-imunidades, particularmente antitireóide. É confirmado pela presença de auto-anticopos, principalmente o anti-GAD65 (1). No HC-FMUSP (41), observamos anti-GAD65 positivo em $4,4 \%$ dos pacientes com DM diagnosticados como DM2. Rosário e cols. (42) verificaram os efeitos benéficos da insulinização precoce nesse grupo.

\section{Definição das síndromes poliendócrinas auto-imunes}

O DMIA se desenvolve também associado a outras doenças auto-imunes, compreendendo três síndromes poliendócrinas auto-imunes (APS) principais: APS-1, APS-2 e IPEX, identificadas pelos determinantes genéticos e humorais (4).

A APS-1 é doença rara, autossômica recessiva, caracterizada pela tríade de candidíase mucocutânea, hipoparatiroidismo e doença de Addison (definida pela presença de dois desses três caracteres). É freqüente a associação de hepatite e várias outras patologias auto-imunes, incluindo DMl em $15 \%$ a $20 \%$. Resulta de mutação do gene AIRE, gene regulador auto-imune, no cromossomo 21 q22.3. Inicia a transcrição de antígenos periféricos nas células epiteliais medulares do timo cuja expressão é importante para a maturação e seleção negativa de células T que reagem contra antígenos próprios $(4,12)$.

A APS-2 é a mais freqüente. DMIA é associado a imunoendocrinopatias que incluem: insuficiência adrenal primária (doença de Addison), doença de Graves, tiroidite auto-imune, myasthenia gravis e doença celíaca. A presença de duas ou mais associações (que podem incluir outras doenças auto-imunes) define a APS-2. A maioria dessas endocrinopatias está associada a alelos HLA-DR3, com predomínio no sexo feminino.

A síndrome IPEX (disfunção imune, poliendocrinopatia, enteropatia ligada ao X) é rara e deve-se à mutação do gene FoxP3, fator de trancrição essencial para a geração das células T CD4+CD25+ reguladoras, que regulam a tolerância periférica a auto-antígenos. As crianças desenvolvem DMl já nos dez primeiros dias de vida, evidenciando a importância dessas células reguladoras (4).

Assim, auto-anticorpos contra outros órgãos e tecidos são freqüentes e ocorrem em $20 \%$ a $30 \%$ dos portadores de DMIA, relacionados especialmente ao aumento da idade, duração do diabetes e sexo feminino. As principais patologias observadas são: 


\section{Doença Auto-imune Tiroidiana}

Presente em $15 \%$ a $30 \%$ dos portadores de DMl versus $10 \%$ a $13 \%$ da população geral. Em um seguimento de 20 anos, o hipotiroidismo ocorreu em $80 \%$ dos pacientes com antiperoxidase ou antitireoglobulina positivos (12). Mantovani e cols. (43), em Minas Gerais, avaliaram 383 pacientes DMlA com idade de 0,9 a 25 anos e duração do diabetes de $9,3 \pm 5,8$ anos. Destes, $16,7 \%$ tinham anticorpos antitireóide positivos, particularmente as meninas. A prevalência de tiroidite aumentava com a idade e tinha relação com outras doenças auto-imunes.

\section{Doença Celíaca}

Presente em $4 \%$ a $9 \%$ dos pacientes, DMlA (versus 1:3000 na população geral). Até $75 \%$ destes têm anomalias na biópsia. O diagnóstico requer a suspeita clínica e o screening é feito com determinação do anticorpo antitransglutaminase, o mais sensível e específico marcador do processo auto-imune. $\mathrm{O}$ diagnóstico requer biópsia do intestino delgado. As características clínicas podem ser leves e incluem alterações do crescimento, dor abdominal e flatulência, infertilidade, alterações da mineralização óssea, hipocalcemia com deficiência de vitamina $\mathrm{D}$, alterações psiquiátricas e neurológicas. Há risco aumentado de malignidade, especialmente linfoma gastrointestinal (12). Tanure e cols. (44), em Minas Gerais, observaram a prevalência de doença celíaca em $2,6 \%$ de 263 crianças com DMlA avaliadas. Os anticorpos podem já se associar à composição corpórea alterada (menor $\mathrm{Z}$ escore para peso, BMI e circunferência do braço) (45). Queiroz e cols. (HC-FMUSP - dados não publicados) analisaram 121 crianças com DMlA - 4,9\% tinham anticorpos antitransglutaminase e anti-endomísio positivos. Esses dados necessitam confirmação com biópsia.

\section{Doença de Addison}

Presente em $0,5 \%$ dos pacientes versus $1: 10.000$ na população geral. Os auto-anticorpos anti-21-OH são extremamente raros na população geral e incidem em $1 \%$ a $2 \%$ dos DMlA. Na evolução desses pacientes há, inicialmente, aumento de atividade de renina, seguida de aumento dos níveis de ACTH e redução do cortisol após estímulo (12).

Em São Paulo (FMUSP), Mainardi-Novo e cols. (46) observaram a seguinte prevalência de auto-anticorpos em pacientes DMIA. Os anticorpos mais freqüentes foram: antitiroglobulina $(21 \%)$ e antiperoxidase $(21 \%)$, seguidos de antinúcleo $(16,3 \%)$, fator reumatóide $(5,7 \%)$, anticélula parietal $(5,6 \%)$ e anti-21OH (5\%). Outros auto-anticorpos como antimúsculo liso, antimitocôndria, anticitoplasma de neutrófilos, antipeptídeo cíclico citrulinado e antimicrossomal fígado/rim tipo I foram negativos.

$\mathrm{O}$ risco de auto-imunidade é aumentado também em familiares de pacientes. Cerca de $8 \%$ desses familiares têm doença tiroidiana auto-imune e até $6 \%$ têm doença celíaca (12).

A associação dessas patologias tem origem em determinantes genéticos comuns, descritos na tabela 2 .

Tabela 2. Genes associados ao DMIA e a outras doenças auto-imunes (12).

\begin{tabular}{ll}
\hline Genes & Doenças associadas \\
HLA & \\
DR3-DQ2, DR4-DQ8 (DRB1*0405 e *0406 & DM1 \\
DR3-DQ5 & Doença auto-imune tiroidiana \\
DR3-DQ2 & Doença celíaca \\
DR3-DQ2, DR4-DQ8 (DRB1*0404) & Doença de Addison \\
MIC_A & DM1 \\
& Doença celíaca \\
\hline PTPN22 & Doença de Addison \\
& DM1 \\
\hline CTLA4 & Doença auto-imune tiroidiana \\
& Doença de Addison \\
\hline
\end{tabular}


Diferentemente dos auto-anticorpos antipâncreas, esses auto-anticorpos estão entrando na rotina dos endocrinologistas. São de fácil determinação e detectam a auto-imunidade órgão-específica antes do desenvolvimento da doença clínica. Detecção precoce tem o potencial de impedir significante morbidade relacionada ás doenças não diagnosticadas, que afetam o crescimento, o ganho de peso, o controle do diabetes, a função gonadal e o bem-estar.

No entanto, apenas parte dos portadores de autoanticorpos desenvolvem a doença clínica. A freqüência do screening e o seguimento dos portadores dos anticorpos são controversos. Embora não haja consenso, há várias recomendações de avaliação da função tiroidiana (TSH, T4 livre e auto-anticorpos) e para doença celíaca (anticorpos antitransglutaminase) ao diagnóstico e, a seguir, a cada 1 a 2 anos. A ADA (1) recomenda dosagem anual de TSH e o screening para doença celíaca, ao diagnóstico e na presença de sintomas. O uso preventivo de levotiroxina em portadores de auto-anticorpos e função tiroidiana normal não é indicado, pois não parece impedir a falência glandular, embora possa ser útil na redução de bócio (47).

Não há recomendações para screening de doença de Addison, mas alguns autores sugerem dosar anti-2 $1 \mathrm{OH}$ ao diagnóstico. Se positivo, fazer o teste de estímulo com ACTH.

\section{CONCLUSÕES}

DMlA é patologia complexa, envolvendo fatores genéticos e ambientais, levando à destruição auto-imune das células-beta. Avanços em imunogenética trouxeram enorme contribuição ao conhecimento da patogênese do DMlA, às suas diferentes manifestações clínicas e patologias associadas. $\mathrm{O}$ diagnóstico e o tratamento do acometimento auto-imune de outros tecidos, particularmente o tiroidiano, são importantes na redução de comorbidades.

\section{REFERÊNCIAS}

1. American Diabetes Association. Diagnosis and classification of diabetes. Diabetes Care. 2007;30 (Suppl 1):S42-7.

2. Hanafusa T, Imagawa A. Fulminant type 1 diabetes: a novel clinical entity requiring special attention by all medical practitioners. Nat Clin Pract Endocrinol Metab. 2007;3(1):36-45.

3. Pozzilli P, Buzzetti R. A new expression of diabetes: double diabetes. Trends Endocrinol Metab. 2007;18(2):52-7.

4. Jahromi MM, Eisenbarth GS. Cellular and molecular pathogenesis of type 1A diabetes. Cell Mol Life Sci. 2007;64(7-8):865-72.
5. Karvonen M, Viik-Kajander M, Moltchanova E, Libman I, LaPorte R, Jaakko T. Incidence of childhood type 1 diabetes worldwide. Diabetes Care. 2000;23(10):1516-26.

6. Eisenbarth GS, Lafferty K. Type 1 diabetes: cellular, molecular and clinical immunology. Disponível em: http://www.uchsc. edu/misc/diabetes/books.html.

7. Pihoker C, Gilliam LK, Hampe CS, Lernmark A. Autoantibodies in diabetes. Diabetes. 2005;54 Suppl 2:S52-61.

8. Kantárová D, Buc M. Genetic susceptibility to type 1 diabetes mellitus in humans. Physiol Res. 2007;56(3):255-66.

9. Alizadeh BZ, Koeleman BP. Genetic polymorphisms in susceptibility to type 1 diabetes. Clin Chim Acta. 2008;387(1-2):9-17.

10. Kelly MA, Rayner ML, Mijovic CH, Barnett AH. Molecular aspects of type 1 diabetes. Mol Pathol. 2003;56:1-10.

11. Park Y. Functional evaluation of the type 1 diabetes (T1D) susceptibility candidate genes. Diabetes Res Clin Pract. 2007;77 (Suppl 1):S110-5.

12. Barker JM. Clinical review: type 1 diabetes-associated autoimmunity: natural history, genetic associations, and screening. J Clin Endocrinol Metab. 2006;91(4):1210-7.

13. Reveille JD. The genetic basis of autoantibody production. Autoimmun Rev. 2006;5(6):389-98.

14. Kawabata $Y$, Ikegami $H$, Kawaguchi $Y$, Fujisawa $T$, Shintani $M$, Ono M, et al. Asian-specific HLA haplotypes reveal heterogeneity of the contribution of HLA-DR and DQ haplotypes to susceptibility to type 1 diabetes. Diabetes. 2002;51:545-51.

15. Davini E, Silva MER, Alves LI, Correia MRS, Fukui RT, Latrônico AC, et al. O genótipo I/I do locus VNTR do gene da insulina confere risco independente para diabetes mellitus tipo 1 nos pacientes sem os genótipos DRB1 e DQB1 de susceptibilidade. Arq Bras Endocrinol Metab. 2005;49 (Suppl 2):S876.

16. Alves C, Meyer I, Vieira N, Toralles MBP, LeMaire D. Distribuição e freqüência de alelos e haplotipos HLA em brasileiros com diabetes melito tipo 1. Arq Bras Endocrinol Metab. 2006;50(3):436-44.

17. Nejentsev S, Howson JM, Walker NM, Szeszko J, Field SF, Stevens $\mathrm{HE}$, et al. Localization of type 1 diabetes susceptibility to the MHC class I genes HLA-B and HLA-A. Nature. 2007;450 (7171):887-92.

18. Törn C, Gupta M, Nikitina Zake L, Sanjeevi CB, Landin-Olsson M. Heterozygosity for MICA5.0/MICA5.1 and HLA-DR3-DQ2/ DR4-DQ8 are independent genetic risk factors for latent autoimmune diabetes in adults. Hum Immunol. 2003;64(9):902-9.

19. Bell GI, Horita S, Karam JH. A polymorphic locus near the human insulin gene is associated with insulin-dependent diabetes mellitus. Diabetes. 1984;33:176-83.

20. Undlien DE, Hamaguchi K, Kimura A, Tuomilehto-Wolf E, Swai $A B$, McLarty DG, et al. IDDM susceptibility associated with polymorphisms in the insulin gene region. A study of blacks, caucasians and orientals. Diabetologia. 1994;37:745-9.

21. Hauache OM, Reis AF, Oliveira CS, Vieira JG, Sjoroos M, llonen J. Estimation of diabetes risk in Brazilian population by typing for polymorphisms in HLA-D-DQ, INS and CTLA-4 genes. Dis Markers. 2005;2:139-45.

22. Hanukoglu A, Mizrachi A, Dalal I, Admoni O, Rakover Y, Bistritzer $Z$, et al. Extrapancreatic autoimmune manifestations in type 1 diabetes patients and their first-degree relatives: a multicenter study. Diabetes Care. 2003;26:1235-40.

23. Ikegami $H$, Awata $T$, Kawasaki $E$, Kobayashi $T$, Maruyama $T$, Nakanish K, et al. The association of CTLA4 polymorphism with type 1 diabetes is concentrated in patients complicated with autoimmune thyroid disease: a multicenter collaborative study in Japan. J Clin Endocrinol Metab. 2006;91(3):1087-92. 
24. Redondo MJ, Eisenbarth GS. Genetic control of autoimmunity in type 1 diabetes and associated disorders. Diabetologia. 2002;45:605-22.

25. Ueda H, Howson JM, Esposito L, Heward J, Snook H, Chamberlain $G$, et al. Association of the T-cell regulatory gene CTLA4 with susceptibility to autoimmune disease. Nature. 2003;423(6939):506-11.

26. Gamberini M, Correia MRS, Davini E, Alves L, Mainardi-Novo DTO, Miura I, et al. Associação do polimorfismo +49 A/G no exon 1 do gene CTLA-4 com diabetes melito tipo 1 e suas apresentações clínicas. Arq Bras Endocrinol Metab. 2006;50:S180.

27. Bottini N, Muscumeci L, Alonso A, Rahmouni S, Nika K, Rostamkhani $M$, et al. A functional variant of lymphoid tyrosine phosphatasis associated with type I diabetes. Nat Genet. 2004;36:337-8

28. Criswell LA, Pfeiffer KA, Lum RF, Gonzales B, Novitzke J, Kern $M$, et al. Analysis of families in the multiple autoimmune disease genetics consortium (MADGC) collection: the PTPN22 $620 \mathrm{~W}$ allele associates with multiple autoimmune phenotypes. Am J Hum Genet. 2005;76(4):561-71.

29. Chelala C, Duchatelet S, Joffret ML, Bergholdt R, Dubois-Laforgue $D$, Ghandil P, et al. PTPN22 R620W functional variant in type 1 diabetes and autoimmunity related traits. Diabetes. 2007;56(2):522-6.

30. Gamberini M, Crisostomo LG, Mainardi-Novo DT, Longhi MT, Davini E, Alves LI, et al. Genetic Association between the Lymphoid Tyrosine Phosphatase Locus (LYP/PTPN22) with type 1 diabetes in caucasians. Program of the $89^{\text {th }}$ Annual Meeting of the Endocrine Society, Toronto, CA, 2007, poster session.

31. Oliveira CS, Hauache OM, Vieira JG, Maciel RM, Sjoroos M, Canani $\mathrm{LH}$, et al. The ala45Thr polymorphism of NEUROD1 is associated with type 1 diabetes in Brazilian women. Diabetes Metab. 2005;31:599-602.

32. Kavvoura FK, loannidis JP. Ala45Thr polymorphism of the NEUROD1 gene and diabetessusceptibility: a meta-analysis. Hum Genet. 2005;116:192-9.

33. Mathieu C, Badenhoop K. Vitamin D and type 1 diabetes mellitus: state of art. Trends Endocrinol Metab. 2005;16:261-6.

34. Turpeinen H, Hermann R, Vaara S, Laine A, Simell O, Knip M, et al. Vitamin $D$ receptor polymorphisms: no association with type 1 diabetes in the finnish population. Eur $\mathrm{J}$ Endocrinol. 2003;149:591-6.

35. Guo S, Magnuson VL, Schiller JJ, Wang X, Ghosh S. Metaanalysis of vitamin $D$ receptor polymorphisms and type 1 diabetes: a HuGE Review of Genetic Association Studies. Am J Epidemiol. 2006;164:711-24.

36. Mory DB, Rocco ER, Miranda WL, Kasamatsu T, Crispim F, Dib SA. Diferenças na relação dos polimorfismos do gene do receptor da vitamina $D$ e a secreção de insulina nos indivíduos com diabetes melito tipo 1. Arq Bras Endocrinol Metab. 2007;51 (Supll 1):S498.

37. Akerblom HK, Vaarala O, Hyoty H, llonen J, Knip M. Environmental factors in the etiology of type 1 diabetes. Am J Med Genet. 2002;115:18-29.
38. Achenbach P, Bonifacio E, Koczwara K, Ziegler AG. Natural history of type 1 diabetes. Diabetes. 2005;54 (Suppl 2):S25-31.

39. Vandewalle CL, Falorni A, Svanholm S, Lernmark A, Pipeleers DG, Gorus FK. High diagnostic sensitivity of glutamate decarboxylase autoantibodies in insulin-dependent diabetes mellitus with clinical onset between age 20 and 40 years. The Belgian Diabetes Registry. J Clin Endocrinol Metab. 1995;80(3):846-51.

40. Kasse CA, Miranda WL, Callari LEP, Sá JR, Dib AS. Auto-anticorpos antiilhota em diabéticos tipo 1 de diagnóstico recente e parentes de primeiro grau brasileiros. Arq Bras Endocrinol Metab. 1998;42(1):45-52.

41. Silva MER, Fukui RT, Correia MRS, Ursich MJM, Nasser M, Rocha DM, et al. Anticorpos antiilhotas de Langerhans (ICA) em pacientes com diabetes mellitus (DM) com ínicio na idade adulta. Arq Bras Endocrinol Metab. 1993;37:103.

42. Rosário PW, Reis JS, Fagundes TA, Calsolari MR, Amim R, Silva $\mathrm{SC}$, et al. Latent autoimmune diabetes in adults (LADA): usefulness of anti-GAD antibody titers and benefit of early insulinization. Arq Bras Endocrinol Metabol. 2007;51(1):52-8.

43. Mantovani RM, Mantovani LM, Dias VM. Thyroid autoimmunity in children and adolescents with type 1 diabetes mellitus: prevalence and risk factors. J Pediatr Endocrinol Metab. 2007;20(6):669-75.

44. Tanure MG, Silva IN, Bahia M, Penna FJ. Prevalence of celiac disease in Brazilian children with type 1 diabetes mellitus. $J$ Pediatr Gastroenterol Nutr. 2006;42(2):155-9.

45. Simmons JH, Klingensmith GJ, McFann K, Rewers M, Taylor $\mathrm{J}$, Emery LM, et al. Impact of celiac autoimmunity on children with type 1 diabetes. J Pediatr. 2007;150(5):461-6.

46. Mainardi-Novo DTO, Gamberini M, Longhi MT, Alves LI, Queiroz MS, Fukui RT, et al. Non-islet autoantibodies (non-isletAAb): prevalence and association with PTPN22 1858T in Brazilian Type I Diabetes Mellitus (DMI) Patients. Arq Bras Endocrinol Metabol. 2007; Supll 1:S103.

47. Karges B, Muche R, Knerr I, Ertelt W, Wiesel T, Hub R, et al. Levothyroxine in euthyroid autoimmune thyroiditis and type 1 diabetes: a randomized, controlled trial. J Clin Endocrinol Metab. 2007;92(5):1647-52

Endereço para correspondência:

Maria Elizabeth Rossi da Silva

Rua João Moura, 627, conj. 72

05412-911 - São Paulo, SP

E-mail: mbeth@usp.br 